\title{
OS LIMITES JURÍDICOS DO PROJETO PARENTAL NO BRASIL CRÍTICA ESTRUTURAL À MULTIPARENTALIDADE
}

\author{
Maria Rita de Holanda Silva Oliveira*
}

\begin{abstract}
Sumário: Introdução -2 . O uso da autonomia parental na realidade social e jurídica brasileira - 3. Liberdade e Família na relação parental - Intervenção Estatal e limites da autonomia na constituição e no exercício da filiação. - 4. O Locus da Multiparentalidade na doutrina. - 5. A tese de repercussão geral 622 do STF e seus reflexos na doutrina brasileira - Conclusão - Referências.
\end{abstract}

\section{INTRODUÇÃO}

O Brasil, em seu atual contexto, lastreia-se na liberdade do planejamento familiar ao casal, preceituada no artigo $226, \$ 77^{\circ}$ da norma Constitucional, devendo o Estado garantir os recursos educacionais e científicos para o exercício desse direito. ${ }^{1}$ O dispositivo é regulamentado pela lei ordinária 9263/96, denominada Lei do Planejamento Familiar, que o define como o conjunto de açôes de regulação da fecundidade

* Mestre em Direito das Relaçôes Sociais pela PUC/SP e Doutora em Direito Civil pela UFPE, membro do Grupo de Pesquisa Constitucionalização das Relações Privadas da UFPE CONREP

1 BRASIL, Constituição da República Federativa. <http://www.planalto.gov. br/ccivil_03/constituicao/constituicaocompilado.htm>. Acesso em: 26/04/2018.

Art. 226. A família, base da sociedade, tem especial proteção do Estado. (...) $\$ 7^{\circ}$ Fundado nos princípios da dignidade da pessoa humana e da paternidade responsável, o planejamento familiar é livre decisão do casal, competindo ao Estado propiciar recursos educacionais e científicos para o exercício desse direito, vedada qualquer forma coercitiva por parte de instituições oficiais ou privadas. 
•• Direito Civil: Estudos | Coletânea do XV Encontro dos Grupos de Pesquisa - IBDCivil

que garanta direitos iguais de constituição, limitação ou aumento da prole pela mulher, pelo homem ou pelo casal. ${ }^{2}$

Conforme se depreende, a garantia é para direitos iguais tanto para o indivíduo considerado singularmente, seja do gênero feminino ou masculino, como para o casal (entenda-se heterossexual ou homossexual), para fins de constituição, aumento ou diminuição da prole.

A regra merece reflexão quanto ao seu alcance e densidade, considerando que o próprio sentido de liberdade para o direito só admite condutas que possam atender a vontade individual e do casal, quando não há comprometimento de outras esferas da individualidade ou da coletividade.

A história da emancipação do direito de família Brasileiro iniciou a sua trajetória de maior abertura com a possibilidade de dissolução do casamento no ano de 1977. Posteriormente consolidou-se na possibilidade da pluralidade das entidades familiares, albergada pelos tipos expressos e implícitos autorizados pela cláusula aberta do artigo 226, caput da CF/88.

Essa emancipação, contudo, se efetivou mais na esfera conjugal do que na esfera parental, em reconhecimento a uma autonomia existencial. Essa autonomia é caracterizada de forma híbrida, combinando a vontade e o interesse privado (autonomia da vontade e autonomia privada).

$\mathrm{Na}$ esfera da parentalidade a intervenção estatal aumentou em proteção à criança e ao adolescente, sujeito de direito vulnerável na constituição do estado de filiação, e que recebeu proteção integral e estatutária. Nessa esfera, portanto, o sentido da liberdade para o direito deve ser equacionado com o sentido da solidariedade, que envolve responsabilidades.

A solidariedade é principalmente um compromisso pelo qual as pessoas se obrigam umas as outras e cada uma delas à todas. Nesse sentido, o seu primeiro locus é no campo da moral, mas foi apreendido pelo direito em razão da situação jurídica em que alguns grupos se encontram. A família é um deles.

A sua primeira expressão na lei reside no inciso I do artigo $3^{\circ}$ da Constituição da República Federativa do Brasil, enquanto objetivo fundamental da República. ${ }^{3}$

2 BRASIL, Lei 9263/1996. Lei do Planejamento Familiar. <http://www.planalto.gov. br/ccivil_03/leis/L9263.htm>. Acesso em: 26 abril 2018.

3 BRASIL. Constituição da República Federativa do Brasil. <http://www.planalto.gov. br/ccivil_03/constituicao/ConstituicaoCompilado.htm>. Acesso em: 22 de janeiro de 2016.

Art. $3^{\circ}$ Constituem objetivos fundamentais da República Federativa do Brasil:

I - construir uma sociedade livre, justa e solidária; 
Além disso, se encontra insculpida no artigo 227 do diploma Constitucional, estabelecendo obrigações para o Estado, família e sociedade no que diz respeito à criança e ao adolescente, sujeito de direito principal, nas relações familiares e para o Estado. ${ }^{4}$

Trata-se de princípio previsto na Convenção Internacional dos direitos da criança no ano de 1989, bem como no Estatuto da Criança e do Adolescente, em seu artigo $4^{\circ}$, correspondente a assistência moral, material e afetiva que é devida entre cônjuges, companheiros e parentes, nos limites de legitimidade estabelecidos pela lei, segundo Paulo Lobo.

Este Princípio pode vir a fundamentar uma ampliação de responsabilidades parentais, para além do que foi estabelecido pela legislação civil vigente, nas novas formatações familiares, ampliando a legitimidade de assistência material e imaterial para os parentes afins, no que tange aos enteados, por exemplo, enquanto crianças e adolescentes, ainda que em caráter subsidiário, mas não gera necessariamente direito sucessório ou implica na mudança de estado de filiação, e é capaz de harmonizar inúmeros conflitos.

O Princípio também se insere na perspectiva dos direitos humanos e soma-se às demais estratégias de proteção integral à criança e ao adolescente, consagrando uma lógica voltada a assegurar a prevalência e a primazia do interesse superior da criança e do adolescente. ${ }^{6}$

Os direitos reconhecidos às crianças e aos adolescentes decorrem de sua peculiar condição de ser humano em desenvolvimento. Como consequência, o estado e a sociedade devem assegurar todas as oportunidades e facilidades, a fim de lhes facultar o pleno desenvolvimento, das capacidades físicas, mentais, morais, espirituais e sociais, em condiçôes de liberdade e dignidade.

II - garantir o desenvolvimento nacional;

III - erradicar a pobreza e a marginalização e reduzir as desigualdades sociais e regionais;

IV - promover o bem de todos, sem preconceitos de origem, raça, sexo, cor, idade e quaisquer outras formas de discriminação.

4 BRASIL. Constituição da República Federativa do Brasil. <http://www.planalto.gov. br/ccivil_03/constituicao/ConstituicaoCompilado.htm>. Acesso em: 22 de janeiro de 2016.

Art. 227. É dever da família, da sociedade e do Estado assegurar à criança, ao adolescente e ao jovem, com absoluta prioridade, o direito à vida, à saúde, à alimentação, à educação, ao lazer, à profissionalização, à cultura, à dignidade, ao respeito, à liberdade e à convivência familiar e comunitária, além de colocá-los a salvo de toda forma de negligência, discriminação, exploração, violência, crueldade e opressão.

5 LOBO, Paulo. Direito civil. Famílias. São Paulo: Saraiva, 2015, p. 57.

6 PIOVESAN, Flávia et al. Temas de direitos humanos. São Paulo: Saraiva, 2010, p. 337. 
Ocorre que a garantia de tais capacidades geram obrigações de fazer e de não fazer aos seus responsáveis diretos, e isso já se inicia na expectativa de seu surgimento, na esfera da elaboração do projeto parental, a fim de garantir a existência de seres com dignidade mínima ao seu pleno desenvolvimento.

A solidariedade impõe deveres que são preventivos e também corretivos e além disso, é irrenunciável.

Portanto, o valor da liberdade em nosso mandamento Constitucional terá grande importância para o exercício da autonomia e o sentido que lhe deve ser atribuído nas relações existenciais.

Como elemento central a liberdade pressupõe a possibilidade de uma escolha. Relembrando Kant, Bodin ${ }^{7}$ ressalta que, no que diz respeito ao conteúdo da dignidade, a humanidade das pessoas reside no fato de serem elas racionais, dotadas de livre-arbítrio e de capacidade para interagir com os outros e com a natureza, e portanto será "desumano", isto é, contrário à dignidade humana, tudo aquilo que servir para reduzir a pessoa (o sujeito de direitos) à condição de objeto, tudo o que permitir uma sua instrumentalização.

A reflexão sobre a liberdade não se afasta da concepção da dignidade humana acima referenciada, tão pouco da responsabilidade.

Bodin $^{8}$ ressalta ainda o novo paradigma da civilística, considerando as mudanças ocorridas na passagem do direito moderno ao pós-moderno:

O mundo da segurança do século XVIII deu lugar a um mundo de inseguranças e incertezas: em segundo lugar, a ética da autonomia ou da liberdade foi substituída por uma ética da responsabilidade ou da solidariedade; enfim, e como consequência das duas assertivas anteriores, à tutela à liberdade (autonomia) do indivíduo foi substituída pela noção de proteção à dignidade da pessoa humana.

$\mathrm{Na}$ mencionada equação entre a solidariedade e a liberdade, a imposição excessiva da solidariedade anula a liberdade; e a liberdade desmedida é incompatível com a solidariedade. Ponderados os seus conteúdos, tornam-se complementares. Regulamenta-se a liberdade em prol da solidariedade social, isto é da relação de cada um com o interesse geral e esse livre desenvolvimento é possibilitado pela redução da desigualdade.

O maior desafio do direito nesse século talvez resida na busca de uma zona que permita o estabelecimento de um compromisso aceitável entre ao valores fundamentais comuns, com os necessários enquadramento éticos e morais refletidos na lei, e os

\footnotetext{
MORAES, Maria Celina Bodin de. Op. cit., p. 186.

8 MORAES, Maria Celina Bodin de. Op. cit., p. 47.
} 
espaços de liberdade, os mais amplos possíveis, de forma a permitir a cada um a escolha de seus atos e a condução da sua vida particular, de seu projeto de vida.?

Há talvez um excesso de individualismo na ideia de que conceber um filho seja um direito dos pais, e em razão disso teriam eles o arbítrio para a escolha da forma da concepção, do processo elaborativo de prevenção de doenças ou mesmo de sexagem, e ainda de buscarem a participação direta de pessoa alheia ao projeto, para ceder o uso de um órgão (gestação subrrogada), considerando que se tem em mãos, as técnicas necessárias à isso. Não há que se proporcionar, todavia, nenhuma garantia a tais pais, que também não garanta o direito de futuras gerações ou de terceiros envolvidos no projeto.

No século XIX, carecendo de direitos políticos e sociais, a liberdade era absoluta para quem detinha patrimônio e a autonomia dos privados contrapunha-se à ordem pública e aos interesses da coletividade. Dessa forma, no liberalismo jurídico a dicotomia entre o direito público e o privado era latente, e esta regia a vida jurídica enquanto que aquele seria apenas uma moldura de proteção, diferentemente da atualidade.

Os direitos reprodutivos, por exemplo, embora insiram-se na temática dos direitos humanos, devem ser exercidos com responsabilidade porque do resultado de seu exercício advirá outra pessoa, que por sua vez tem proteção de seus direitos fundamentais.

A prática na sociedade, com o funcionamento dos Centros de Reprodução humana, resume o exercício pleno dessa liberdade a uma única condição: o consentimento informado das partes com relação aos procedimentos. Será ele suficiente? Os próprios efeitos do projeto parental aparecem reelaborados pelas partes no contrato, como se este passasse a ter uma prevalência sobre a lei. Conforme se verá adiante, a técnica da gestação subrrogada, segundo alguns autores, consiste em um dos locus da multiparentalidade.

Ainda que se reconheça a existência de uma realidade social palpitante de descobertas científicas e possibilidades e naturalizemos alguns procedimentos, não podemos deixar de refletir sobre a incidência categorial de nossos institutos jurídicos.

Dessa forma, e visando harmonizar as liberdades hoje exercidas na realidade social, com os preceitos e limites de nossa liberdade jurídica, procurar-se-á identificar os problemas que podem advir na consideração da multiparentalidade como regra. Trata-se portanto, de uma crítica estrutural e não moral.

9 MORAES, Maria Celina Bodin de. Na medida da pessoa humana. Estudos de direito civil-constitucional. Rio de Janeiro: Renovar, 2010, p. 75. 
•• Direito Civil: Estudos | Coletânea do XV Encontro dos Grupos de Pesquisa - IBDCivil

\section{O USO DA AUTONOMIA PARENTAL NA REALIDADE SOCIAL E JURÍDICA BRASILEIRA}

A reflexão sobre a liberdade no projeto parental é imprescindível para a identificação ou não de limites a serem observados segundo o nosso sistema jurídico.

O termo "autonomia", no direito privado, sofreu uma série de variaçōes conceituais, que terminou por aDJetivá-lo, ora como autonomia da própria vontade, em um exercício do interesse subjetivo de quem a exercesse, ora como os limites impostos pela própria ordem Constitucional, que embora mantivesse o seu caráter privatista, ao mesmo tempo o regulava em observância a uma igualdade material a ser considerada nas relações jurídicas entre os particulares.

Daí decorre a distinção histórica entre as expressões Autonomia da Vontade, no contexto do Estado Liberal, Autonomia Privada no contexto do Estado Social e a Autonomia existencial.

Uma ideia central ao humanismo e ao Direito Moderno é o da autonomia privada em sentido amplo, como trabalha Daniel Sarmento ${ }^{10}$, enquanto dimensão fundamental da noção mais ampla de liberdade. Para o autor, não cabe ao Estado, a qualquer instituição, pessoa humana ou coletividade, e nem mesmo à Constituição estabelecer os fins que cada pessoa humana deve perseguir, os valores e crenças que deve professar.

Sarmento ${ }^{11}$ trabalha esse sentido da autonomia privada, não apenas na esfera da liberdade contratual e negocial para fins patrimoniais como também na esfera existencial.

Para Perlingieri, ${ }^{12}$ a negociação que tem por objeto situações subjetivas não patrimoniais - de natureza pessoal e existencial - deve ser colocada em relação à cláusula geral de tutela da pessoa humana. Assim, os atos de autonomia teriam, portanto, fundamentos diversificados; porém encontram um denominador comum na necessidade de serem dirigidos à realização de interesses e de funçôes que merecem tutela e que são socialmente úteis. E na utilidade social existe sempre a exigência de que atos e atividades não contrastem com a segurança, a liberdade e a dignidade humana. A autonomia se apresenta, portanto, como atuação não somente de direitos subjetivos, mas também de deveres de solidariedade não somente material e econômica, mas também social e familiar.

10 SARMENTO, Daniel. Direitos fundamentais e relaçôes privadas. Rio de Janeiro: Lumen Juris, 2004, p. 173.

11 SARMENTO, Daniel. Direitos fundamentais e relaçôes privadas, cit., 2004, p. 173.

12 PERLINGIERI, Pietro. Perfis de direito civil. 2. ed. Rio de Janeiro: Renovar, 2002, p. 18-19. 
A construção das concepções parentais na filiação no tempo levou a legislação brasileira a um ideal binário a ser observado como formação à estabilidade existencial. Em outras palavras o ser humano passou a ser mais completamente inserido e apto ao seu desenvolvimento, quando sob os cuidados de pelo menos duas pessoas, sendo estas primordialmente, as que lhes deram origem pelo nascimento ou que optarem pelo exercício das funções parentais paterna e materna, independentemente do gênero, na busca de uma formação global da personalidade humana.

A definição do conteúdo da autonomia nas relaçōes familiares é de suma importância, principalmente para a identificação de limites na esfera do planejamento familiar.

Observe-se que o conceito de biparentalidade, na atualidade, vai além do critério biológico, considerando o reconhecimento da sociedade e de nosso ordenamento jurídico, de que o estado de filiação não se confunde com a origem biológica do ser humano, embora estes não sejam excludentes, como bem pontua Paulo Lobo. $^{13}$

Da mesma forma e já em razão de outras vicissitudes históricas, como a própria emancipação da mulher na família e na sociedade, o exercício do planejamento familiar de filiação por uma única pessoa, seja o pai ou a mãe, advenha do critério biológico ou socioafetivo, ingressa em uma permissão moral e jurídica, na denominada Monoparentalidade.

Do exposto, indagamos: haveria a plena liberdade no exercício do planejamento familiar? Podemos definir o número de filhos que pretendemos ter, mas estará em nossa livre escolha a forma como os teremos e os criaremos? Os elementos fáticos colhidos pela norma jurídica e que legitimam o estado de filiação podem ser afastados pela vontade paterna/materna de origem? A filiação poderia ser livremente declarada pelo exercício da vontade ou estaria sujeita a parâmetros mínimos a serem observados pela norma e na necessidade de sua qualificação?

$\mathrm{Na}$ análise inicial da liberdade e da dignidade, foi possível verificar que para o direito a sua plenitude somente será alcançada se devidamente guiada a buscar valores que não podem ser apenas individuais, mas também da própria coletividade.

A autonomia existencial entre a antiga autonomia da vontade e a atual autonomia privada, guarda preceito de ambas e aí reside a sua complexidade. Há que se respeitar escolhas, sentimentos e subjetividades, mas as condutas voltadas às

13 LOBO, Paulo. Estado de filiação e origem genética: uma distinção necessária. Disponível em: <http://www2.cjf.jus.br/ojs2/index.php/revcej/article/viewFile/633/813>. Acesso em: 07/07/2014. 
relações existenciais não se prestam apenas à realização individual dos desejos, mas na combinação destes às condutas que resguardem a dignidade, o respeito, a solidariedade e deveres de cuidado na assistência material e imaterial.

$\mathrm{Na}$ autonomia existencial, contudo, apesar desse traço híbrido, teremos relações mais valoradas no desejo e na livre escolha, mas que também guardam deveres, e relações que nos submetem a muito mais deveres do que propriamente desejos, não obstante também nos satisfaçam emocionalmente. Assim, ela se opera distintamente na relação conjugal e na relação parental.

$\mathrm{O}$ recuo do Estado na intervenção de determinação da relação conjugal foi inverso à sua maior inserção configuração das relaçôes parentais que envolvem crianças e adolescentes, identificando estes enquanto sujeitos de direito que impõem limites comportamentais parentais.

Em razão disso, dentre as correntes libertaristas e utilitaristas acima mencionadas, deduzimos que o nosso sistema jurídico está mais voltado à última quando trata de relação parental, já que envolve a pessoa ainda em seu pleno desenvolvimento.

Assim, respondendo aos questionamentos acima ter-se-ia que não há liberdade plena na constituição de um projeto parental, a não ser em seu quantitativo. Quando se trata da forma do planejamento familiar, esta nem sempre estará ligada ao elemento intencional. Os elementos fáticos colhidos pela norma jurídica e que legitimam o estado de filiação não podem ser afastados pela vontade paterna/materna de origem e dessa forma o estado jurídico de filiação está sujeito a enquadramentos normativos e na necessidade de sua qualificação.

\section{LIBERDADE E FAMÍLIA NA RELAÇÃO PARENTAL - INTERVENÇÃO ESTATAL E LIMITES DA AUTONOMIA NA CONSTITUIÇÃO E NO EXERCÍCIO DA FILIAÇÃO.}

Imaginando o planejamento familiar na esfera quantitativa, tendo por foco os "pais", a nossa norma jurídica se estruturou em um sistema binário, que decorre de uma legitimação não apenas natural da concepção, como também de uma concepção psicossocial na formação da personalidade do indivíduo.

Ao inserir expressamente a família monoparental, para fins de proteção do Estado, a Constituição Federal relativizou a binariedade, com o propósito de proteção o menor e, portanto, no fato de ser esta advinda de um fator não necessariamente pretendido pela parte (o abandono, o divórcio, a viuvez), por não estar em seu processo intelectual a finalidade de projetar a filiação para o exercício individual. 
A monoparentalidade, portanto, tem proteção Constitucional, mas a sua interpretação literal não permite a restrição desta ao caráter de involuntariedade do projeto parental individual, suscitando uma série de outros questionamentos.

A presente análise, contudo, destina-se não ao mínimo (monoparentalidade), mas ao máximo (multiparentalidade) da fixação dos liames parentais de filiação. A "multiparentalidade" também implicaria na relativização do sistema binário para admitir que a filiação possa ser exercida por mais de dois "pais" ou "mães. Além disso, não possui previsão expressa em nosso ordenamento, mas foi recentemente acolhida pelo Supremo Tribunal Federal na Tese de Repercussão Geral 622, que será analisada.

Nas regras atuais da filiação no Código Civil Brasileiro, há uma diferença no tratamento da filiação, quando se aborda os polos da maternidade e da paternidade: o reconhecimento voluntário oriundo da simples declaração extrajudicial, apenas seria admitido com relação ao pai, cuja incerteza acompanhou a sua definição por longos anos, e mesmo assim, havendo anuência materna, se não há a conjugalidade.

Ainda assim, o reconhecimento voluntário paterno exige declaração verdadeira quanto à origem biológica, posto que a falsa declaração dessa origem resulta em conduta tipificada como crime contra a fé pública em nosso ordenamento. Além disso, na esfera civil, a falsa declaração pode viciar o ato em sua validade gerando a possibilidade de sua anulação, presente o erro ou a ignorância com relação ao fato da origem, pelo pai. A esse respeito, vale o registro das construçóes teóricas em torno da verdade da filiação socioafetiva declarada, não obstante proveniente de conduta criminosa e viciada, se presentes os elementos da posse do estado de filiação. Incide aqui para essa consideração a norma relativa ao melhor interesse da criança e do adolescente, se a convivência houver se estabelecido.

João Baptista Villela ${ }^{14}$, ressalta o fortalecimento dos vínculos socioafetivos como determinadores da parentalidade:

Se o fundamento capital da paternidade é de natureza afetiva e não biológica, torna-se imperioso abrir maior espaço, entre nós, à posse do estado de filho, cujo papel no direito de família não pode ficar limitado ao âmbito da prova, senão que deve alcançar a própria constituição do status familiae.

[...]

Na medida, pois, que a paternidade se constitui pelo fato, é fácil perceber que a posse do estado de filho pode entrar em conflito com a presunção pater is est. Igualmente o podem outras situações que não resultam da norma, mas de comportamentos concretos.

14 VILLELA, João Baptista. O modelo constitucional da filiação: verdade \& superstições. Revista Brasileira de Direito de Família. ano I, n. 2, jul./set. 1999, p. 132. 
Fabíola Lobo ${ }^{15}$ critica a timidez de nossa legislação civil para o estabelecimento dos parâmetros da chamada posse de estado de filiação, trazendo à baila o modelo Francês ${ }^{16}$, que detalha as condições de qualificação da filiação socioafetiva de forma mais ampla e detalhada, por meio de uma reunião de fatos, como o nome, o tratamento, a continuidade, a notoriedade e o reconhecimento da autoridade pública.

Para a autora, portanto, a denominada "adoção à brasileira" entre nós brasileiros, tida por nosso sistema como um tipo criminal, deve ser reconhecida sob o viés da filiação, se presentes os elementos da posse de estado de filho, sendo necessário desconstruir a ideia da "ilegalidade" para lhe reconhecer verdade, se essa for a hipótese que atender ao melhor interesse da criança.

Já a simples declaração materna perante o registro, por lei, não terá eficácia se não estiver acompanhada da prova de que decorreu a filiação da gestação e do parto. A maternidade sempre foi certa ao direito, em razão da prenhez e do parto, necessitando o oficial de Registro Civil da prova obtida na Declaração de nascido vivo emitida pelo obstetra ou Centro de saúde (maternidade) responsável. Dessa forma, a definição de maternidade precede qualquer declaração, posto que se qualifica pela gestação e pelo parto.

O problema na análise da incidência de uma norma sobre determinado fato está, muitas vezes, na compreensão de conceitos que, sendo produto de uma atividade de abstração, os leva a desligarem-se, demasiadamente, da realidade, lembra Francisco Amaral ${ }^{17}$. Daí a necessidade de se adotar uma concepção pluralista, interdisciplinar e construtivista, máxime na análise de situaçōes jurídicas existenciais.

15 LÔBO, Fabíola Albuquerque. Adoção à brasileira e a verdade real do registro civil. Disponível em: <http://www.ibdfam.org.br/publicacoes/anais/detalhes/714/V\%20Congresso $\% 20$ Brasileiro\%20de\%20Direito\%20de\%20Fam\%C3\%ADlia>. Acesso em: 19 de maio de 2015.

16 FRANÇA.CodeCivil.<http://www.legifrance.gouv. fr/affichCode.do;jsessionid=8ECC7750 579D9581D3BCE8CAB22DD96A.tpdila23v_3?idSectionTA=LEGISCTA000006150014 \&cidTexte $=$ LEGITEXT000006070721 $\&$ dateTexte $=20150519>$. Acesso em: 22 de janeiro de 2016.

Article 311-1 La possession d'état s'établit par une réunion suffisante de faits qui révèlent le lien de filiation et de parenté entre une personne et la famille à laquelle elle est dite appartenir. Les principaux de ces faits sont: $1^{\circ}$ Que cette personne a été traitée par celui ou ceux dont on la dit issue comme leur enfant et qu'elle-même les a traités comme son ou ses parents; $2^{\circ}$ Que ceux-ci ont, en cette qualité, pourvu à son éducation, à son entretien ou à son installation; $3^{\circ}$ Que cette personne est reconnue comme leur enfant, dans la société et par la famille; $4^{\circ}$ Qu'elle est considérée comme telle par l'autorité publique; $5^{\circ} \mathrm{Q}$ u'elle porte le nom de celui ou ceux dont on la dit issue. Acesso em: 19 de maio de 2015.

17 AMARAL, Francisco. Direito civil: introdução. 6. ed. rev., atual. e aum. Rio de Janeiro: Renovar, 2006, p. 8. 
Para a elaboração jurídica, segundo o jurista, seriam necessárias as denominadas categorias, que são quadros onde os elementos da vida jurídica se agrupam, por afinidade, e fora dos quais não se reconhece eficácia. E tais categorias nós já temos.

Conforme anunciado anteriormente, a concepção jurídica de filiação em nosso Direito positivo Brasileiro, por meio das categorias elencadas, teve como momento histórico determinante inicial, no Código Civil de 1916, os valores da época ligados à realidade típica de uma sociedade colonial, patriarcal e matrimonialista da família, estabelecendo a partir daí sérias exclusões, como a legitimação da filiação advinda apenas do casamento e a proibição de reconhecimento de outros filhos incestuosos, adulterinos e espúrios.

Dessa forma, corroboramos que a história do direito de família brasileiro foi pautada por uma profunda exclusão, onde toda e qualquer autonomia era subjugada em nome de um padrão comportamental influenciado por valores morais "cristãos" que condenavam pela culpa, o cidadão que fugisse de tais preceitos, aplicando-lhe sanções que variavam entre as perdas materiais e imateriais, além da própria ilegitimidade que lhe era impingida, em total desproteção e neutralização de seus efeitos jurídicos. Havia apenas uma categoria de filhos nesse contexto: os denominados legítimos, por advirem da relação conjugal, ficando os demais à margem de qualquer qualificação e proteção.

A família transferiu muitas de suas funções do passado a outras instituições sociais (Estado, Igreja, Escola, empresa) e todo esse processo de mudança, se opera para a liberdade, que resultou em uma fuga das amarras rígidas e conceituais da família, mas isso não dispensa a busca de sua legitimação e reconhecimento pelo coletivo. ${ }^{18}$

A mesma mudança que se operou dentro do casamento - dos interesses extrínsecos à mútua realização dos cônjuges (a reinvenção), parece operar-se nos vários arranjos da atualidade, que se auto intitulam com o objetivo familiar, numa postura de autossuficiência que parece querer dispensar qualquer necessidade de legitimação, com base em um único argumento: a própria existência/a primazia do concreto, da realidade e do fato. Um outro abismo com o qual deveremos ter o cuidado, sob pena de comprometer o próprio Estado de Direito.

A busca de uma composição que possa estabelecer um equilíbrio entre as restriçōes individuais necessárias e a realização pessoal é onde reside toda a problemática, que resulta ora em verdadeiras contradiçôes no sistema ora em apenas aparentes contradições.

18 LOBO, Paulo. A repersonalização das relaçôes de família, <https://jus.com.br/artigos/5201/a-repersonalizacao-das-relacoes-de-familia>. Acesso em: 22 de janeiro de 2016. 
Villela ${ }^{19}$ antes mesmo do marco da Constituição Federal de 1988, prenunciou a necessidade de várias modificaçôes, algumas já operadas em nosso sistema, a exemplo da mutabilidade dos regimes de bens, admitida pelo Código Civil de 2002, o conteúdo da Emenda Constitucional 66/2010 e a adoção da interpretação aberta e exemplificativa, utilizada, inclusive, pelo nosso Supremo Tribunal Federal no julgamento das Uniōes Homoafetivas, além de outras que merecem ser refletidas no contexto atual, a partir da premissa de um modelo aberto, proposto pelo autor.

Felizmente, o texto normativo da Constituição Federal de 1988, se afastou do modelo unitário e excludente do casamento como única formação familiar e derivação da filiação, e rompeu com dogmas escravizantes nas relações existenciais, ao prever expressamente, vários tipos de constituição familiar que merecem total proteção do Estado. Além disso, a elaboração exemplificativa permite ao intérprete a inclusão de tipos implícitos, que estejam coadunados com o sentido de sua abrangência, em prol da dignidade humana e da nova finalidade familiar voltada ao bem-estar dos membros que a compõem.

As grandes derivações categoriais da doutrina e da jurisprudência na atualidade advém da ideia equivocada de que o conteúdo dos Princípios Constitucionais pode ser definido em cada caso concreto segundo o juízo de valor do aplicador.

A consolidação da metodologia pós-positivista na doutrina e Tribunais brasileiros tem sinalizado para o crescente perigo do excesso do voluntarismo judicial. A necessária superação do formalismo por uma perspectiva mais flexível e principiológica tem sido efetiva nos Tribunais e agora há um perigo oposto. Não raro as decisões, sem a preocupação com a qualidade dos argumentos levantados, são desprovidas de motivaçôes racionais e substanciais. ${ }^{20}$

Sobre a distinção entre Regras e princípios, enquanto pertencentes a uma mesma categoria que é a norma jurídica, não há dúvidas de que a interpretação conforme a Constituição surge como metodologia mais flexível à concretização dos valores, permitindo a mutação da norma sem a necessária alteração de seu texto.

Porém, destaca Humberto Ávila ${ }^{21}$ que, a exaltação da importância dos Princípios não apequena a função das regras, e a mera instituição de valores sem a instituição

19 VILELLA, João Baptista. Liberdade e família. Edição da Faculdade de Direito da UFMG, Publicação n. 33, Belo Horizonte: MG, 1980, p. 9-45.

20 MORAES, Maria Celina Bodin de. Na medida da pessoa humana. Estudos de direito civil-constitucional. Rio de Janeiro: Renovar, 2010, p. 56.

21 ÁVILA, Humberto. Teoria dos princípios. Da definição à aplicação dos princípios jurídicos. São Paulo: Malheiros, 2013, p. 29. 
de comportamentos deve ser ultrapassada, da mesma forma que a automática aplicação da regra pela subsunção.

$\mathrm{Na}$ busca da definição de uma dimensão da autonomia na esfera familiar, registramos também o posicionamento de Portalis $^{22}$, que reconhece ter a família uma função social, que estaria atrelada à preservação da moral de um modelo definido de sociedade.

Pianovski ${ }^{23}$ esclarece o sentido do social, afirmando que não se trata de pensar juridicamente a família como instrumento para a sujeição da pessoa de modo a domesticá-la, mas no oferecimento do espaço para a auto constituição da pessoa, no exercício da liberdade de coexistir. $\mathrm{O}$ autor reitera a contraposição aos modelos anteriores, onde esta não era traço relevante para se pensar a família, o que não importa em afirmar que a família do século XXI possa ser pensada apenas em termos de liberdade.

Principalmente na relação parental é evidente que para o exercício da autoridade, há óbvia restrição imediata à liberdade negativa de seus destinatários. É óbvio que os espaços de auto constituição devem existir mesmo na sujeição com poder autoritário. ${ }^{24}$ Para a eficácia, portanto, da relação paterno filial, é de suma importância que o direito não apenas reconheça a sua não ilicitude, mas também a sua validade, além de apreende-la como fattispecie de natureza familiar, chancelando os efeitos decorrentes dessa relação. Não basta, portanto, a liberdade negativa (de se auto excluir) como também não basta a liberdade positiva (de se auto incluir).

A interpretação exemplificativa do rol de entidades familiares, não autoriza todos os arranjos que se pretendam designar como família, pela simples declaração da vontade dos sujeitos, principalmente em havendo a suscitação de conflito de interesse e a exigência de decisão do Estado para dirimir e apresentar soluções, quando então deverá reconhecer ou não os seus efeitos.

Balizamentos eficaciais são inevitáveis. De qualquer forma não mais se trata da busca da proteção dos arranjos, como no passado, mas sim de cada membro componente desse arranjo familiar.

22 PORTALIS, Jean-Étienne-Marie. Discours Préliminaire du Premier Projet du Code Civil. <http://www.justice.gc.ca/fra/apd-abt/gci-icg/code/page04.html>. Acesso em: 20 de abril de 2015.

23 RUZYK, Carlos Eduardo Pianovski. Institutos fundamentais do direito civil e liberdade(s): repensando a dimensão funcional do contrato, da propriedade e da família. Rio de Janeiro: GZ Ed., 2011, p. 315.

24 TEIXEIRA, Ana Carolina Brochado. Família, guarda e autoridade parental. Rio de Janeiro: Renovar, 2005, p. 212. 
Integrar um arranjo familiar nem sempre é uma opção livre, haja vista que por vezes decorre de situações e eventos inegáveis, e o nascimento é um deles. O direito apreende o fato biológico do nascimento como fato capaz de gerar efeitos na esfera da dimensão familiar da filiação e a autonomia negativa constitui-se uma conduta ilícita dado que à ninguém é conferido o direito de não querer ser pai ou mãe após a consumação do fato, estabelecendo-se, por ficção, a irrenunciabilidade do Poder Familiar como regra.

Segundo Paulo Lôbo ${ }^{25}$, a paternidade e a maternidade lidam com seres em desenvolvimento que se tornarão pessoas humanas em plenitude, exigentes de formação até quando atinjam autonomia e possam assumir responsabilidades próprias, em constante devir.

Nesse sentido, a responsabilidade não é apenas dos pais, mas também de todos os que integram as relações de parentesco ou grupo familiar. Em caráter mais amplo, o art. 227 da Constituição impõe à família, à sociedade e ao Estado, deveres em relação à criança e ao adolescente concernentes à preservação da vida, à saúde, à educação familiar e escolar, ao lazer, à profissionalização, à cultura, à dignidade, à liberdade, e à convivência familiar.

O direito de Família assim, embora se situe atualmente em um espaço democrático, não dispensa a necessidade de intervenção Estatal, que é revelada em muitas disposições Constitucionais, na medida em que exige garantia da implementação de políticas públicas protetivas. A vedação prevista no $\$ 7^{\circ}$ do artigo 226 da Constituição Federal de 1988, na esfera do planejamento familiar, deixa claro que a intervenção do Estado dar-se-á para garantir o projeto parental, mas nunca para impor formas coercitivas ou direcionar modelos numéricos ou qualitativos.

Assim, tal proteção não deve interferir na forma de origem do parentesco de filiação, se consanguíneo/genético natural, se genético artificial, se civil (adoção) ou decorrente da convivência familiar pela posse de estado de filho, hipóteses estas que qualificam a filiação no sistema Brasileiro.

Contudo, o Estado ao legislar, impõe requisitos para o estabelecimento de algumas das filiações à exemplo do instituto da Adoção.

Infelizmente, o que vivemos hoje, nas palavras de Tércio $^{26}$ é uma crise de paradigma do direito legislado e codificado. Segundo o autor, passamos da centra-

25 LÔBO, Paulo. Famílias contemporâneas e as dimensôes da responsabilidade, <http://jus.com.br/ $\operatorname{artigos} / 25363 /$ familias-contemporaneas-e-as-dimensoes-da-responsabilidade>, aceso em 19 de maio de 2015.

26 FERRAZ JUNIOR, Tercio Sampaio. O direito entre o futuro e o passado, 2014, p. XV. 
lidade da lei para a centralidade da jurisdição, em sentido amplo: os tribunais judiciais, tribunais de arbitragem, agências administrativas com poder judicante (com tribunais e conselhos administrativos), órgãos da administração direta (que dizem o direito por meio de sentenças, acórdãos, decisões interlocutórias, resoluções, pareceres normativos).

\section{O LOCUS DA MULTIPARENTALIDADE NA DOUTRINA.}

De acordo com Catalan ${ }^{27}$, a multiparentalidade estaria tangenciada dentro das seguintes possibilidades:

(a) o movimento incessante de construção e de destruição dos laços afetivos nas famílias recompostas; (b) a utilização de material genético de alguém como matéria-prima na fecundação de um novo ser; (c) a adoção não destruidora do passado; (d) a gestação de substituição ou, ainda, (e) a história dos núcleos de poliamor.

No Brasil, a possibilidade é visualizada por muitos doutrinadores e pelo STF e estaria baseada em razão da existência de vários arranjos reais, portanto no que se denomina de primazia da realidade, no exercício da afetividade ou ainda no atendimento ao melhor interesse da criança.

Assim, seria o locus propício para a multiparentalidade: a convivência familiar no parentesco por afinidade (padrastos e enteados); a manutenção da convivência familiar com os pais de origem, não obstante já haver a filiação registral socioafetiva; e as declaraçôes de vontade $a b$ initio, de projeto triparental, para os que se utilizam das técnicas de reprodução humana.

Essas três situações são reconhecidas por tais entendimentos, como possibilidades fáticas, capazes de promover a relativização do sistema binário da filiação.

É importante ressaltar, que a desconstrução casuística da biparentalidade quantitativa, no reconhecimento de mais de dois vínculos simultâneos no registro e no exercício da parentalidade da filiação, não é acolhida como regra pelo nosso sistema, o que não significa dizer que, quando o menor de alguma forma já se encontrar irremediavelmente inserido nesse contexto, ou talvez ainda não tenha vivenciado qualquer outra forma de inserção, não possa vir a ser protegido e amparado com os deveres de responsabilidade múltiplos para o seu sustento e desenvolvimento, considerando-se a estratégia da guarda compartilhada que é imposta na divisão de convivência familiar e deveres. Ainda assim, poderá enfrentar

27 CATALAN, Marcos. Um ensaio sobre a multiparentalidade: explorando no ontem pegadas que levarão ao amanhã, <https://www.academia.edu/4341570/Um_ensaio_sobre_a_multiparentalidade>. Acesso em: 07 de fevereiro de 2016. 
dificuldades não apenas com a legitimação da sociedade, como também com a incidência de determinados preceitos normativos.

Pela lei, um indivíduo só poderia ter até dois "pais" (pai e mãe; dois pais ou duas mães) em seu registro civil.

Catalan ${ }^{28}$, já mencionado, critica o sistema binário, afirmando ser o mesmo excludente de situaçôes palpáveis na realidade social e baseado em um simplismo lógico, não mais condizente com os mosaicos familiares da atualidade.

$\mathrm{O}$ autor justifica a sua crítica, fundado também em sociedades primitivas que dentro de sua cultura, sempre relativizaram essa binariedade, na acomodação de seus valores e interesses. Identifica ainda os fatores que teriam levado ao sistema binário, de forma negativa, a partir da busca de uma certeza patrimonialista em Roma, que se preocupou com a transmissão do patrimônio familiar, e mesmo da influência do cristianismo que incutiu a ideia de sacralidade indissolúvel do casamento.

Registra ainda o autor, que no Brasil, a virilidade patriarcal e a racionalidade patrimonialista foram os vetores que informaram a codificação que veio a lume em 1916, e que, portanto, tudo isso causou marcas indeléveis na história da família contemporânea, estrutura que não tem como ser aprisionada no interior de um código e que varia consoante o espaço e o tempo nos quais tenha que ser pensada.

Não se propõe, contudo, enxergar as verdades parentais, apenas na ótica de serem entes pré-moldados, mas sim de manter um mínimo a ser observado na ordem parental, sem o qual, se ingressaria em campos difusos de definição dos direitos familiares e incompatíveis.

Contrariando um pouco o posicionamento do autor, o direito codificado não precisa ser reducionista em sua interpretação, na medida em que poderá considerar as responsabilidades parentais e o convívio familiar, independentemente de mudança de estado de filiação.

Assim, o direito não impede que tais funções sejam exercidas simbolicamente, mas não reconhece que tal aparência venha a legitimar situações jurídicas permanentes. Não se trata de valorizar o imaginário ao invés do real. O compromisso da ciência do direito em um sistema civil law, é o de garantir minimamente, que esse ideal se estabeleça. Outrossim, não se pode dispersar, na ideia de primazia da realidade pelo desejo, pelo amor e pelo sentimento, posto que estes fogem do controle social, inarredável à ciência jurídica. Além disso, esta mesma primazia da realidade

28 CATALAN, Marcos. Um ensaio sobre a multiparentalidade: explorando no ontem pegadas que levarão ao amanhã, <https://www.academia.edu/4 341570/Um_ensaio_sobre_a_multiparentalidade>. Acesso em: 07 de fevereiro de 2016. 
nos remete ao exercício pela má-fé de inúmeras situações jurídicas com intuitos apenas mercenários.

Os defensores da multiparentalidade, terminam por trabalhar o fenômeno apenas na situação concreta, sem maiores elaborações sobre as repercussões jurídicas nos conflitos familiares ou mesmo no direito sucessório, e sem a abstração necessária para a compreensão do fenômeno de forma geral.

Imagine-se, por exemplo, a regra insculpida no direito sucessório com relação à ordem de vocação hereditária. Prevê o artigo 1836 que na ausência de descendentes são chamados a suceder os ascendentes, em concorrência com o cônjuge sobrevivente. ${ }^{29} \mathrm{Em}$ seguida todo o raciocínio é voltado a duas linhas, sendo uma materna e a outra paterna (podendo duas maternas ou duas paternas). A previsão de concorrência do cônjuge é base de um terço ou da metade, na hipótese de haverem dois ascendentes ou apenas um respectivamente. Na hipótese de triparentalidade na ascendência, esta regra transmuda-se automaticamente para o recebimento de um quarto para o cônjuge?

Se não mais houver os ascendentes de primeiro grau, serão chamados a suceder os de segundo grau e nessa hipótese ao cônjuge será reservada a metade e a outra metade, em tese, poderia ser dividida em até seis vezes ao invés de quatro?

Certamente também, ao invés da possibilidade de dois direitos sucessórios com relação aos pais, essa expectativa aumentaria para três, assim como aumentaria a expectativa da divisão da herança com os irmãos unilaterais ou bilaterais que viessem a surgir de qualquer dos três pais ou mães.

Não apenas na esfera patrimonial, mas também pessoal, como se daria o exercício do poder familiar pelos três ou mais? O consentimento para a prática de atos também seria exercido por todos, e a convivência familiar teria que ser ainda mais fracionada. Os conflitos de alienação parental estariam instigados, posto que com o aumento do número dos agentes, de certo há aumento na possibilidade de conflitos pelo dissenso, pela discordância.

Como aferir se em qualquer dessas possibilidades estar-se-ia atendendo ao melhor interesse da criança? E mais, há que se presumir que no aumento da possibilidade de conflitos familiares, ao contrário, estaríamos nos afastando abstramente desse interesse.

29 BRASIL. Lei 10.406 de janeiro de 2012. Código Civil brasileiro, <http://www.planalto.gov. br/ccivil_03/leis/2002/L10406.htm>. Acesso em: 29 de janeiro de 2016.

Art. 1.836. Na falta de descendentes, são chamados à sucessão os ascendentes, em concorrência com o cônjuge sobrevivente. 
Esvai-se em uma simples análise toda a ordem estabelecida, gerando-se uma infinidade de possibilidades e consequentemente instalando-se a insegurança jurídica das relações, pela própria imprevisibilidade do sistema.

Haveria um custo social considerável para a sua implementação e as reformulaçōes na vida social.

Assim, se há a possibilidade de se estabelecer a coerência e trazer uma solução harmônica dentro do sistema para a solução dos conflitos, deve se dar prevalência a esta.

Para que uma decisão judicial venha a dirimir tal conflito, se surgido, será necessário mais do que critérios pessoais ou políticos, e sim a busca de certa estabilidade nas decisões que façam o sistema previsível.

A decisão, no dizer de Lorenzetti ${ }^{30}$, deve atender a uma ordem de raciocínio, que por sua vez é sucessivo:

Primeiro, aplicar a dedução das regras válidas; segundo, controlar esse resultado conforme os precedentes, o resto do sistema legal e as consequências; terceiro - e se restarem problemas, estaríamos diante de um caso difícil onde deve ser aplicada a solução baseada em Princípios; e quarto, se houver paradigmas que definam a solução, serão explicados, devendo ser procurada a sua harmonização.

Essa ordem, por sua vez, não é de subordinação, mas sim de sucessão argumentativa do raciocínio legal.

Aqui não se trata de poder se interpretar e decidir de maneira mais formalista ou menos formalista. $\mathrm{O}$ que se pondera é o estabelecimento de um sistema reitor estável, para que seja delimitado o campo de argumentos permitidos, e flexível, para que se mantenha aberto às modificaçóes. ${ }^{31}$

A relativização do sistema binário para todos os efeitos jurídicos traria algumas consequências, dentre as quais, no mínimo:

a) A potencialização dos conflitos familiares na configuração tripartida do Poder Familiar;

b) A exigência de novos critérios para o direito sucessório, com as respectivas linhas de ascendência (paterna e materna, ou paternas e maternas);

c) A manipulação do status filiae pela vontade, com objetivo exclusivamente patrimonial, na medida em que a inclusão de terceira figura paterna ou materna por trazer maior vantagem financeira;

30 LORENZETTI, Ricardo Luis. Teoria da decisão judicial. São Paulo: RT, 2008, p. 157.

31 LORENZETTI, Ricardo Luis. Teoria da decisão judicial, cit., p. 170. 
d) As soluções jurídicas para os conflitos familiares teriam que ser desmembradas e criadas pelo aplicador do direito em caráter subjetivo, e embora querendo gerar o sentido máximo da justiça na decisão, terminaria por comprometer a própria segurança jurídica das relações.

Diante disso, a primeira conclusão é a de que apesar de atualmente termos como ponto de partida a permissibilidade da multiparentalidade anunciada pelo STF, o ordenamento jurídico brasileiro não comporta a variação da binariedade na filiação em regra, salvo com relação à monoparentalidade, devendo ser observado, portanto o seu caráter EXCEPCIONALÍSSIMO. Da mesma forma, a multiparentalidade possui um outro sentido, ligado a funçôes que são exercidas em prol da criança e do adolescente, com significativo aumento da responsabilidade parental para atendimento desse interesse, mas não de mudança da situação jurídica de filiação, muito menos para atender interesses individuais.

\section{A TESE DE REPERCUSSÃO GERAL 622 DO STF E SEUS REFLEXOS NA DOUTRINA BRASILEIRA}

A paternidade socioafetiva, declarada ou não em registro público, não impede o reconhecimento do vínculo de filiação concomitante baseado na origem biológica, com os efeitos jurídicos próprios.

Recentemente e em paradigmática decisão, o STF ${ }^{32}$, nos autos do RE 898.060/ SC, com Repercussão Geral reconhecida (Tema 622), admitiu a possibilidade de coexistência das filiações biológica e socioafetiva, para todos os fins de direito, ampliando os vínculos parentais e reconhecendo a configuração da Multiparentalidade.

No caso concreto, escolhido como leading case da Repercussão Geral 622, é possível verificar pela leitura da sentença prolatada pelo Juízo da 2a Vara da Família da Comarca de Florianópolis, bem como dos acórdãos proferidos pelo Tribunal de Justiça do Estado de Santa Catarina, que a autora, F. G., é filha biológica de A. N., o que restou comprovado pelo resultado dos exames de DNA produzidos no curso do processo. Todavia, a autora foi registrada como filha de I. G., quando de seu nascimento, dele recebendo, por mais de vinte anos, os cuidados de pai. O acórdão de origem reconheceu a dupla parentalidade, dispondo acerca dos efeitos jurídicos decorrentes do vínculo genético relativos ao nome, alimentos e herança. Contra essa decisão insurgiu-se o pai biológico, por meio da interposição do Recurso Extraordinário ora em comento, sustentando a preponderância da paternidade

32 No RE 898.060/SC, Rel. Min. Luiz Fux, j. 21/09/16, publicado no Informativo n. 840. 
socioafetiva em detrimento da biológica, com fundamento nos artigos $226, \$ \$ 4^{\circ}$ e 7o, 227, caput e $\$ 6^{\circ}, 229$ e 230 da Constituição Federal, posto existir vínculo de parentalidade socioafetiva previamente reconhecido e descoberta posterior da paternidade biológica.

Em seu voto, o relator, Ministro Luiz Fux, ressaltou a importância de não se reduzir o conceito de família a modelos padronizados, além de afirmar a ilicitude da hierarquização entre as diversas formas de filiação, acentuando a necessidade de se contemplar, sob o âmbito jurídico, as variadas formas pelas quais a parentalidade pode se manifestar: "(i) pela presunção decorrente do casamento ou outras hipóteses legais (como a fecundação artificial homóloga ou a inseminação artificial heteróloga - art. 1.597, III a V do Código Civil de 2002); (ii) pela descendência biológica; ou (iii) pela afetividade".

A partir dessa premissa, e afirmada a possibilidade de surgimento da filiação por origens distintas, fundamentou seu voto no supraprincípio da dignidade humana, em "sua dimensão de tutela da felicidade e realização pessoal dos indivíduos a partir de suas próprias configurações existenciais", o que impõe o reconhecimento de modelos familiares diversos da concepção tradicional, para se assentar que tanto os vínculos de filiação construídos pela relação afetiva entre os envolvidos, como os originados da ascendência biológica, devem ser acolhidos em nosso ordenamento, em razão da imposição decorrente do princípio da paternidade responsável, expresso no $\$ 7^{\circ}$, do art. 226, da Constituição.

$\mathrm{Na}$ opinião de Calderón ${ }^{33}$, o STF, ao prever expressamente a possibilidade jurídica da pluralidade de vínculos familiares, permite um claro avanço, uma vez que confere maior dignidade ao vínculo socioafetivo. E o autor destaca, assim como Tartuce $^{34}$, três aspectos principais diante da tese estabelecida na repercussão geral: o reconhecimento jurídico da afetividade, o vínculo socioafetivo e biológico em igual grau de hierarquia jurídica e a possibilidade jurídica da multiparentalidade.

Para Tartuce ${ }^{35}$, a multiparentalidade passou a ser admitida pelo Direito brasileiro, mesmo que contra a vontade do pai biológico, cuja tese firmada possibilita que os filhos acionem os pais biológicos para obter o vínculo de filiação com intuitos alimentares e sucessórios, "em claras demandas frivolas, com finalidade

33 CALDERÓN, Ricardo. Parentalidades simultâneas. Revista IBDFAM. Multiparentalidade: vínculos que se entrelaçam, edi. 29, out./nov. 2016.

34 TARTUCE, Flávio. Direito civil. Direito de Família. 12. ed. Rio de Janeiro: Forense, 2017, v. 5.

35 TARTUCE, Flávio. Direito civil. Direito de camília. 12. ed. Rio de Janeiro: Forense, 2017, v. 5 , p. 449. 
patrimonial pura", seguindo o caminho percorrido pelo STJ e por ele criticado, consubstanciando um dos pontos negativos da premissa fixada.

Para Schreiber ${ }^{36}$, a conclusão alcançada pela decisão do STF é corajosa e ousada, pois considera que o limite máximo à biparentalidade é dogma antiquíssimo. O Tribunal, segundo o autor, de uma única vez; a) reconheceu o instituto da paternidade socioafetiva, mesmo à falta de registro - tema que ainda encontra resistência em parte da doutrina do direito de família; b) afirmou que a paternidade socioafetiva não representa uma paternidade de segunda categoria diante da paternidade biológica; e c) abriu as portas do sistema jurídico brasileiro para a chamada "multiparentalidade". Conclui o autor ${ }^{37}$ que diante de filhos que somente se interessam pelos pais biológicos no momento de necessidade ou ao se descobrirem como potenciais herdeiros de fortunas, competirão aos juizes e tribunais separar o joio do trigo, empregando mecanismos disponíveis na ordem jurídica brasileira para evitar o exercício de uma situação jurídica subjetiva em descompasso com seu fim axiológico-normativo.

Neste sentido, outras discussóes são suscitadas entre os doutrinadores, a exemplo de Lôbo $^{38}$, que entende que a referida decisão não se aplica a qualquer hipótese de filiação não biológica, mas “apenas à situação de filiação socioafetiva consolidada, registrada ou não, que foi contrastada, posteriormente, pelo reconhecimento voluntário ou não de parentalidade biológica”, não devendo ser entendida de modo diverso. Para o autor, a admissão pelo STF da multiparentalidade foi surpreendente ante seu alcance alargado e não esperado pela doutrina da parentalidade socioafetiva - que objetivava o seu reconhecimento jurídico, não podendo ser desafiado por investigação de paternidade/maternidade cumulada com o cancelamento do registro civil com fundamento exclusivo na origem biológica, além da igualdade jurídica de ambas as parentalidades, sem prevalência de qualquer uma delas.

Nesse ponto, é interessante fazer uma análise crítica da decisão, que tem efeitos erga omnes, diante da repercussão geral, que tomou como base para o reconhecimento da multiparentalidade apenas o critério biológico com paternidade socioafetiva já estabelecida e consolidada, para fins meramente patrimoniais.

36 SCHREIBER, Anderson. STF, Repercussão Geral 622: a Multiparentalidade e seus efeitos. Jornal Carta Forense (versão digital), publicado em 26/09/2016. Disponível em: <www.cartaforense.com.br>. Acesso em: 23 fev. 2017.

37 STF, Repercussão Geral 622: a Multiparentalidade e seus Efeitos. Jornal Carta Forense (versão digital), publicado em 26/09/2016. Disponível em: <www.cartaforense.com.br>. Acesso em: 23 fev. 2017.

38 LÔBO, Paulo. Jurista comenta repercussão da tese sobre multiparentalidade fixada pelo STF. IBDFAM, 28/09/16. Disponível em: <www.ibdfam.org.br>. Acesso em: 29 set. 2016. 
A questão foi analisada por Calderón ${ }^{39}$ destacando que na decisão do STF "alguns pontos não restaram acolhidos, como a distinção entre o papel de genitor e pai, bem destacado no voto divergente do Ministro Edson Fachin ${ }^{40}$ ao deliberar sobre o caso concreto".

A evolução da família e do Direito expressam a passagem do fato natural da consanguinidade, que era indispensável para a família patriarcal e exclusivamente matrimonial, para o fato cultural da afetividade, baseada na convivência duradoura com pais socioafetivos, conduzindo a distinção entre pai e genitor ou procriador, pois pai é aquele que cria, e genitor, o que gera. A paternidade deriva do estado de filiação, independentemente da origem (biológica ou não).

Portanto, não há que se confundir o direito de personalidade ao conhecimento à origem genética a que todos têm direito, com o direito à filiação fundada no princípio da Afetividade.

O que se questiona é se é possível o reconhecimento da Multiparentalidade com base apenas no critério biológico, para fins de parentesco biológico concorrente com o parentesco socioafetivo, não estando presente a efetiva afetividade e convivência entre as pessoas que buscam o vínculo parental.

Para Gagliano e Pamplona ${ }^{41}$, o que há de novo "é a decisão do Supremo admitir essa parentalidade plúrima de acordo com o exclusivo interesse do filho, mesmo não havendo sido construída história de vida alguma com o pai biológico".

Indaga-se: há limites para o seu reconhecimento? Entende Aguirre ${ }^{42}$ que o limite para a assunção da Multiparentalidade encontra-se exatamente na existência, ou não, da afetividade, eis que o reconhecimento de vínculos concomitantes só será possível quando existente a socioafetividade entre o pai biológico e o filho, e também comprovada a socioafetividade com outra pessoa que exerça concomitantemente o papel paterno/materno e somente assim seria possível o reconhecimento de vínculos simultâneos.

Mas na divergência das interpretaçooes doutrinarias pode-se vislumbrar a insegurança da aplicabilidade da Tese, que sofrerá os mais diversos entendimentos nas aplicações pelo judiciário.

39 CALDERÓN, Ricardo. Novidades no direito de família: STF acolhe socioafetividade e multiparentalidade. Publicado em 6 abr. 2017. Disponível em: <www.lfg.com.br>. Acesso em: 17 abr. 2017.

40 Não disponibilizado no RE 898.060.

41 GAGLIANO, Pablo Stolze; PAMPLONA FILHO, Rodolfo. Novo curso de direito civil. Direito de familia. 7. ed. São Paulo: Saraiva, 2017, p. 658.

42 AGUIRRE, João. Reflexos sobre a multiparentalidade e a Repercussão Geral 622 do STF, publicado na Revista Eletrônica Direito e Sociedade. Canoas, v. 5, n. 1, 2017. Disponível em: <http://dx.doi.org/10.18316/REDES>. Acesso em: 16 abr. 2017. 
Não há uniformidade, por exemplo, quanto a inversão de tais situações, como a busca do reconhecimento da paternidade socioafetiva não obstante já esteja registrada a biológica; assim como a possibilidade que o ascendente tem de também buscar o reconhecimento biológico que um dia abandonou; enfim, se é a doutrina que deve orientar a jurisprudência a sua diversidade de entendimento também influenciará.

Por essa razão e dúvidas suscitadas é que se buscou a estruturação do sistema para talvez reconhecer que o caminho mais uniforme apenas será encontrado na bibarentalidade, sem prejuízo de que a multiparentalidade possa ocorrer na convivência e até mesmo com a ampliação dos deveres parentais, mas desde que isso não implique em alteração do estado de filiação, que importará, necessariamente, nas consequências sucessórias e nos receios de manipulação dos interesses.

Aguirre $^{43}$ admite essa ponderação ao se posicionar pela não consolidação da Multiparentalidade "se o objetivo for eminentemente patrimonial, com vistas somente à obtenção de benefícios econômicos, tais como um pleito sucessório ou de alimentos em que não tenha existido o vínculo afetivo e represente apenas a busca pelo ganho fácil". E conclui o autor ${ }^{44}$ que "o vínculo meramente biológico não é capaz de produzir os efeitos decorrentes das relaçôes de parentesco, em razão da ausência de afetividade, mas será capaz de garantir o exercício do direito à identidade".

No mesmo sentido, Aguirre ${ }^{45}$ também sustenta que a multiparentalidade não constitui regra em nossa ordem jurídica após a Repercussão Geral 622, não devendo a parentalidade socioafetiva coexistir em todos os casos com a biológica, ressaltando que as relações afetivas podem decorrer de situações em que a socioafetividade esteja presente nas relações com o genitor, mas também com outro sujeito que exerça o papel de pai.

\section{CONCLUSÃO}

O reconhecimento da Multiparentalidade, nos termos atuais exige uma análise apurada e cuidadosa por parte dos julgadores e da doutrina, uma vez que devolveu-se ao judiciário, minado de diversas concepções, a solução que poderá considerar a

43 AGUIRRE, João. Reflexos sobre a multiparentalidade e a Repercussão Geral 622 do STF, publicado na Revista Eletrônica Direito e Sociedade. Canoas, v. 5, n. 1, 2017. Disponível em: <http://dx.doi.org/10.18316/REDES>. Acesso em: 16 abr. 2017.

44 AGUIRRE, João. Reflexos sobre a multiparentalidade e a Repercussão Geral 622 do STF, publicado na Revista Eletrônica Direito e Sociedade. Canoas, v. 5, n. 1, 2017. Disponível em: <http://dx.doi.org/10.18316/REDES>. Acesso em: 16 abr. 2017.

45 AGUIRRE, João. Reflexos sobre a multiparentalidade e a Repercussão Geral 622 do STF, publicado na Revista Eletrônica Direito e Sociedade. Canoas, v. 5, n. 1, 2017. Disponível em: <http://dx.doi.org/10.18316/REDES>. Acesso em: 16 abr. 2017. 
valorização da socioafetividade ou a valorização do critério biológico, independentemente de convivência familiar, como foi o caso julgado da Repercussão Geral.

A decisão em comento trouxe, sem sombra de dúvidas, um novo marco para o direito à filiação, com o reconhecimento jurídico da Afetividade, a igualdade e coexistência das parentalidades biológica e socioafetiva, sem uma excluir necessariamente a outra, e a possibilidade jurídica da Multiparentalidade, mas por outro lado, deixou inúmeros questionamentos que foram aqui destacados.

A simples prova da convivência, de existência de vínculos de afinidade, sem a prova de ausência da convivência no vínculo registral vigente, por si só também não seria suficiente para a invocação da tese cumulativa da socioafetividade pela multiparentalidade e há decisões que são emblemáticas nesse sentido, e que negaram a paternidade e maternidade socioafetiva cumulada com petição de herança, em razão da autora já possuir pais registrais e ter convivido com eles, afastando a busca da filiação socioafetiva como meio de auferir vantagem patrimonial. Dessa forma, ressalta-se o caráter binário da filiação e a necessidade de que em um processo desconstitutivo ou constitutivo de estado de filiação, importe sempre no cancelamento do registro anterior, rejeitando a facilidade da multiparentalidade.

Registre-se uma mudança de postura legal no Direito Brasileiro no passado recente, que afastou a multiparentalidade de nosso sistema. A situação híbrida que era imposta ao adotado entre os seus pais de origem e os pais adotivos, foi eliminada em prol de um modelo definitivo de mudança do estado de filiação. Ou seja, o Brasil detinha uma multiparentalidade legal na adoção simples e em 2002, rompeu esse propósito.

No entanto, há na esfera normativa parâmetros a serem perseguidos, entre os quais: a estabilidade da criança (material e imaterial), a afetividade (afeto e responsabilidade), a sustentabilidade e as referências parentais legitimadas pela moral consensual coletiva.

Trata-se de um equívoco querer moldar toda e qualquer situação existencial a categorias que não lhe comportam, como o da filiação. A harmonização poderá haver dentro do próprio sistema, com a aplicabilidade do instituto da guarda compartilhada que divide responsabilidades, sem estabelecer óbice a que terceiro a exerça e muito menos um parente.

Nesse sentido, há limites estruturais que justificam a presente crítica. Imaginar que, diante da complexidade e mutabilidade das relações existenciais conjugais o direito estará sempre pronto a apreender todos os fatos como jurídico, é nos afastar totalmente dos critérios formais eleitos pelo nosso ordenamento jurídico de origem romano-germânica. 
Manter os critérios na regra geral, por sua vez, não significa valorizar um modelo excludente e hermeticamente imobilizado, mas reconhecê-lo como preferencial diante de tantas variações, admitindo-se a multiparentalidade filial apenas excepcionalmente, quando voltada a valor.

\section{REFERÊNCIAS}

AGUIRRE, João. Reflexos sobre a Multiparentalidade e a Repercussão Geral 622 do STF, publicado na Revista Eletrônica Direito e Sociedade. Canoas, v. 5, n. 1, 2017. Disponível em: <http://dx.doi.org/10.18316/REDES>. Acesso em: 16 abr. 2017.

AMARAL, Francisco. Direito civil: introdução. 6. ed. rev., atual. e aum. Rio de Janeiro: Renovar, 2006.

ÁVILA, Humberto. Teoria dos principios. Da definição à aplicação dos princípios jurídicos. São Paulo: Malheiros, 2013.

BRASIL. Constituição da República Federativa. <http://www.planalto.gov. br/ccivil_03/ constituicao/constituicaocompilado.htm>. Acesso em: 26/04/2018.

BRASIL. Lei 9263/1996. Lei do Planejamento Familiar. <http://www.planalto.gov. br/ ccivil_03/leis/L9263.htm>. Acesso em: 26/04/2018.

BRASIL. Lei 10.406 de janeiro de 2012. Código civil brasileiro, <http://www.planalto. gov. br/ccivil_03/leis/2002/L10406.htm>. Acesso em: 29 de janeiro de 2016.

CALDERÓN, Ricardo. Parentalidades Simultâneas. Revista IBDFAM. Multiparentalidade: vínculos que se entrelaçam, ed. 29, out./nov. 2016.

CATALAN, Marcos. Um ensaio sobre a multiparentalidade: explorando no ontem pegadas que levarão ao amanhã. <https://www.academia.edu/4341570/Um_ensaio_sobre_a_ multiparentalidade>. Acesso em: 07 de fevereiro de 2016.

FERRAZ JUNIOR, Tercio Sampaio. O direito, entre o futuro e o passado. São Paulo: Noeses, 2014.

FRANÇA. Code Civil. <http://www.legifrance.gouv. fr/affichCode.do;jsessioni$\mathrm{d}=$ 8ECC7750 579D9581D3BCE8CAB22DD96A.tpdila23v_3?idSectionTA=LEGISCTA000006150014\&cidTexte $=$ LEGITEXT000006070721 \&dateTexte $=20150519>$. Acesso em: 22 de janeiro de 2016.

GAGLIANO, Pablo Stolze; PAMPLONA FILHO, Rodolfo. Novo curso de direito civil. Direito de família. 7. ed. São Paulo: Saraiva, 2017.

LOBO, Paulo. Estado de filiação e origem genética: uma distinção necessária. Disponível em: <http://www2.cjf.jus.br/ojs2/index.php/revcej/article/viewFile/633/813>. Acesso em: 07/07/2014.

LOBO, Paulo. Direito civil. Famílias. São Paulo: Saraiva, 2015. 
LOBO, Paulo. A repersonalização das relaçōes de família. <https://jus.com.br/artigos/5201/a-repersonalizacao-das-relacoes-de-familia>. Acesso em: 22 de janeiro de 2016. LÔBO, Fabíola Albuquerque. Adoção à Brasileira e a verdade real do registro civil, <http:// www.ibdfam.org.br/publicacoes/anais/detalhes/714/V\%20Congresso\%20Brasileiro \%20de\%20Direito\%20de\%20Fam\%C3\%ADlia>. Acesso em: 19 de maio de 2015.

LÔBO, Paulo. Famílias contemporâneas e as dimensöes da responsabilidade, <http://jus. com.br/artigos/25363/familias-contemporaneas-e-as-dimensoes-da-responsabilidade>, aceso em 19 de maio de 2015.

LOBO, Paulo. Jurista comenta repercussão da tese sobre multiparentalidade fixada pelo STF. IBDFAM, 28/09/16. Disponível em: <www.ibdfam.org.br>. Acesso em: 29 set. 2016.

LORENZETTI, Ricardo Luis. Teoria da decisão judicial. São Paulo: RT, 2008.

MORAES, Maria Celina Bodin de. Na medida da pessoa humana. Estudos de direito civilconstitucional. Rio de janeiro: Renovar, 2010.

PERLINGIERI, Pietro. Perfis de direito civil. 2. ed. Rio de Janeiro: Renovar, 2002.

PIOVESAN, Flávia et al. Temas de direitos humanos. São Paulo: Saraiva, 2010.

PORTALIS, Jean-Étienne-Marie. Discours Préliminaire du Premier Projet du Code Civil. $<$ http://www.justice.gc.ca/fra/apd-abt/gci-icg/code/page04.html>. Acesso em: $20 \mathrm{de}$ abril de 2015.

SARMENTO, Daniel. Direitos fundamentais e relaçôes privadas. Rio de Janeiro: Lumen Juris, 2004.

SCHREIBER, Anderson. STF, Repercussão Geral 622: a multiparentalidade e seus efeitos. Jornal Carta Forense (versão digital), publicado em 26/09/2016. Disponível em: <www.cartaforense.com.br>. Acesso em: 23 fev. 2017.

STF. Repercussão Geral 622: a multiparentalidade e seus efeitos. Jornal Carta Forense (versão digital), publicado em 26/09/2016. Disponível em: <www.cartaforense.com.br>. Acesso em: 23 fev. 2017.

RUZYK, Carlos Eduardo Pianovski. Institutos fundamentais do direito civil e liberdade(s): repensando a dimensão functional do contrato, da propriedade e da família. Rio de Janeiro: GZ Ed., 2011.

TARTUCE, Flávio. Direito civil. Direito de família. 12. ed. Rio de Janeiro: Forense, 2017, v. 5.

TEIXEIRA, Ana Carolina Brochado. Familia, guarda e autoridade parental. Rio de Janeiro: Renovar, 2005.

VILLELA, João Baptista. O modelo constitucional da filiação: verdade \& superstições. Revista Brasileira de Direito de Família, ano I, n. 2, jul./set. 1999.

VILLELA, João Baptista. Liberdade e família. Edição da Faculdade de Direito da UFMG, Publicação n. 33, Belo Horizonte: MG, 1980, p. 9-45. 